\title{
Environmental factors of energy saving for buildings with green roofs at Russian cities
}

\author{
Elena Sysoeva ${ }^{1, *}$, Andrey Benuzh ${ }^{1}$, Margarita Gelmanova ${ }^{1}$, and Aleksey Bogachev ${ }^{1}$ \\ ${ }^{1}$ Moscow State University of Civil Engineering, 26, Yaroslavskoye shosse, 129337, Moscow, Russia
}

\begin{abstract}
Green roofs can increase the energy efficiency of the coating by lowering the temperature of the roof in the summer, and in winter - by possibly increasing the overall resistance to heat transfer of the coating. In addition, they reduce the volume and intensity of runoff due to the moisture saturation of the substrate and the processes of total evaporation, improve the microclimate of the urban area: increase air humidity, soften the effect of the urban heat island, reduce noise pollution, significantly reduce the volume and density of dust masses in densely built-up areas of large megacities. Experimental and analytical researches are needed to create a methodology for scientific justification of the ecological efficiency of the green roof design and the district model, to confirm the need and possibility making of a green roof in the II climatic zone of Russia, taking into account the temperature difference (up to $50^{\circ} \mathrm{C}$ ) in summer and winter seasons.
\end{abstract}

\section{Introduction}

For 25 years, UN conferences have been held (the last one was held in 2012 in Rio De Janeiro "Rio+20") on the problems of pollution and total environmental change that can lead to disasters [1-3]. International documents such as the "Rio Declaration", "Agenda 21"," Statement of principles on the management, conservation and sustainable development of all types of forests"," Convention on biodiversity"," framework conference on climate "have been adopted. These conferences put forward declarations to address current issues and the right of people to a healthy environment and achieve sustainable development.

The territories of large cities and megacities with a population density of more than 4,000 people per $\mathrm{km}^{2}$ face numerous environmental problems and it is becoming an increasingly urgent problem to maintain the working capacity and health of citizens in their territories. Impervious surfaces interrupt the natural hydrological cycle of storm water by disrupting the infiltration and recharge of groundwater. Excessive storm water can exceed the capacity of drainage systems, which leads to flooding of urban road systems. This fills the city with harmful substances, disrupts the transport system and worsens the environmental safety of territories [4-6]. Important task is to manage the evapotranspiration of green roofs, which depends on both the climate conditions (humidity and temperature, solar radiation, wind conditions) and the density and type of plantings. Experiments show that annual precipitation evaporation rates are $45 \%-70 \%$. This value depends on the efficiency of the substrate and the

* Corresponding author: SysoevaEV@mgsu.ru 
speed of water movement in substrate [7]. Moreover, the area of green roofs can regulate the evapotranspiration rate of a limited territory.

The problem of urbanized territories is also the increased noise level, which causes a stressful state of people, sharply worsens hearing, slows down mental ability, as a result worsens working capacity. And an increase in the level of nervousness can lead to a decrease in the average possible standard of living. A. O. Ioffe, O. I. Gavrilova, S. E. Stetsenko found that with the usual noise background of a city with traffic of 2-3 thousand cars per hour, noise pollution reaches $77-90 \mathrm{~dB}$. An experiment was made on the basis of Petrozavodsk state University. The results showed that in the rooms under the green roof, the noise background is reduced to $8 \mathrm{~dB}$, and over the green roof, a decrease in sound reflections on the roof is recorded to $3-10 \mathrm{~dB}$ [8-9].

A major problem of urbanized territories is the global change in the temperature background of large cities [10-13]. The increase in the average temperature of the Earth's climate system, which has been occurring for more than 100 years, is based on an anthropogenic factor and may reach $2-4,8^{\circ} \mathrm{C}$ in the next decade [14-15]. The use of green roof technology will help reduce the roof surface temperature from 70 to $40^{\circ} \mathrm{C}$ [16] and reduce the temperature of the urban environment by $2-40^{\circ} \mathrm{C}$. The task of large megacities is also to protect the roof from overheating and UV radiation, while increasing their durability. Thanks to the green roof, the temperature around the construction site decreases, thus reducing the possibility of creating a heat island in cities. Green buildings mitigate the "heat island effect" by equalizing the temperature of building surfaces in an urban environment [17]. Reducing the building's overheating in the summer period leads to an increase in the building's profitability up to $23 \%$ per year of the total cost of air conditioning, which is important for the II climate zone of Russia.

One of the most important advantages of a green roof is its energy-saving function. Chinese scientists conducted experiments on existing green roofs of office buildings and determined that energy consumption decreased depending on the climatic conditions of different territories from 15 to $30 \%$ [18-25]. It can be noted that when the roof temperature increases, volatile substances and compounds are formed from bituminous roofing materials that are harmful to human health. If there is a green roof, this feature disappears [26].

An important advantage of the green roof is its ability to capture and absorb solid dust particles up to $50 \%$ and reduce the concentration contaminants. In the territories of countries such as Germany, France, the Czech Republic, etc. according to the results of observations, an increased concentration of $\mathrm{CO}_{2}$ is absorbed by green roofs, including dust and heavy metals by $6-52 \%$. A roof with green spaces (for example, in the form of a lawn) provides an increase in oxygen intake. A $150 \mathrm{~m}^{2}$ lawn releases oxygen per year, which is enough for 100 people to breathe.

It is necessary to consider the profitability, efficiency and environmental improvement of the territory with the development of a large area of roof landscaping and over a long period. Short-term research is not possible to assess the factor of improving the health and emotional state of citizens living in large cities. A significant eco-effect within the city is possible with a significant share of green roofs from the total number of roofs ( 20\%) [27-29].

Every year in Germany, the Czech Republic, England, etc. Supplement landscaping with new surfaces of green roofs, conducting field and laboratory studies [30-39]. 


\section{Materials and methods}

Energy efficiency is a set of characteristics that reflect the ratio of the useful effect of the energy resources use to the costs of them produced in order to obtain such an effect, in relation to products, technological process, legal entity, individual entrepreneur [40]. For many years, the EU Commission's directives on energy and transport regulating the "energy efficiency class" have been in force in the world. For buildings and structures, the energy efficiency class is the ratio of the calculated or actual specific heat consumption for heating or ventilation per square meter to the established standard consumption. The specific energy consumption itself depends on the geometry of the building, thermal characteristics and air infiltration properties of the enclosing structures [41]. In addition, the overall energy efficiency depends on the environmental friendliness of the construction and operation of the building, which is achieved by producing environmentally friendly building materials and reducing the release of carbon dioxide $\left(\mathrm{CO}_{2}\right)$ [42].

To date, improving the energy efficiency of a building at the design or renovation stage of a building is of great importance. The main ways to achieve the required energy efficiency due to the roof are to increase the total heat resistance of the multi-layer roof system, that is, by increasing the thickness of the effective insulation (mineral wool or extruded polystyrene) [43]. This method does not take into account other thermal characteristics of the roof structure that affect the heat loss of the building. The use of technologies for greening the roof can solve many problems to improve energy efficiency due to the fact that the heat resistance of a multi-layer green roof system is equivalent to the value of the heat resistance of the traditional one [44-46] and has a number of energy-saving advantages.

One of the important parameters that affect energy efficiency is the internal air exchange of the building [47]. The effect of air exchange can be tracked in a simplified formula for the specific heat consumption for heating and ventilation of a building during the heating period, which does not take into account the operation of thermoregulators and excess heat over heat loss during the heating period:

$$
q_{h}^{p}=k_{o b}+k_{\text {vent }}-k_{h}-k_{h a}
$$

where $k_{o b}$ - specific heat protection characteristic of the building; $k_{\text {vent }}$ - specific ventilation characteristic of the building; $\mathrm{k}_{h}$ - specific characteristic of household heat release of the building; $k_{h a}$ - specific characteristic of heat access to the building from solar radiation of the building through translucent enclosing structures [48]. The terms $\mathrm{k}_{h}$ and $k_{h a}$ are accepted the same in the case of a traditional standard and green roof, since landscaping will not affect these characteristics.

To prove the effectiveness of a green roof it is necessary to consider the $k_{v e n t}$ characteristic, which consists of the sum of the specific characteristics that depends on the supply air of the $k_{p r}$ and the infiltrating air of the $k_{i n f}$.

$$
k_{\text {vent }}=k_{p r}+k_{\text {inf }}
$$

In turn, the $k_{\text {inf }}$ directly depends on the amount of air infiltrating into the building through the enclosing structures of the $G_{i n f}$, which is determined from the total amount of air passing through such enclosing structures as Windows and doors, but does not take into account the air passing through the thickness of the roof. To determine the difference between the energy efficiency of traditional and green roofs, it is necessary to take into account the air infiltration through the attic floor array $G_{\text {roof. }}$

$$
G_{\text {inf }}=G_{w}+G_{d}+\left[G_{\text {roof }}\right]
$$


where the amount of air in the roof (without taking into account the pressure difference) is determined by the ratio of the roof area to the total air permeability resistance:

$$
G_{\text {roof }}=\frac{A_{\text {roof }}}{R_{u, \text { roof }}} \cdot \Delta p_{\text {roof }}
$$

\section{Discussion}

In Russia, no research has yet been conducted, both theoretical and experimental, to study the thermophysical processes in the layers of the green roof structure, the impact of this structure on the quality of water and air, energy efficiency of buildings, and improving the psychological and emotional state of people. For the introduction of green technology in Russia, theoretical and then experimental justification of the effectiveness of green roofs in various climatic zones of the country during the full annual cycle is necessary.

The accumulated experience over the past 20 years shows that there is not enough deep study of the research topic among Russian researchers, in contrast to foreign ones. In the world in recent years has undertaken a number of studies, including experimental, on the effect of green roofs on air quality, the quality and quantity of runoff from a green roof, but the peculiarities of the climate of Russia with the possibility of sharp changes in outdoor air temperature in summer and winter are not taken into account.

In addition to the above advantages, green roofs increase the energy efficiency of buildings, soften the effect of urban heat island, and also contributes to a comfortable stay of people in the building. Despite the large number of proposed approaches to the solution of problems of environmental safety subject of greening roofs, a significant number of publications of foreign researchers devoted to the study of the features of the design and calculation of green roofs, comprehensive studies to determine the parameters of them with consideration of climatic features that are available filtration, drainage materials, substrate types, species composition of plants on the territory, an unique solution to this problem with the use of green roofs is not still nowadays. In Russia, there are no national standards for the calculation and design of operated green roofs, and, as a result, the materials, configuration and installation methods of these roofs can vary widely from case to case. Differences in calculation methods, approaches, designs, and conditions for using green roofs obviously lead to different calculation results and regulatory requirements, and require further efforts to improve methods for assessing environmental safety.

\section{Conclusions}

Green roofs can increase the energy efficiency of the coating by lowering the temperature of the roof in the summer, and in winter - by possibly increasing the overall resistance to heat transfer of the coating. In addition, they reduce the volume and intensity of runoff due to the moisture saturation of the substrate and the processes of total evaporation, improve the microclimate of the urban area: increase air humidity, soften the effect of the urban heat island, reduce noise pollution, significantly reduce the volume and density of dust masses in densely built-up areas of large megacities (Fig. 1). 


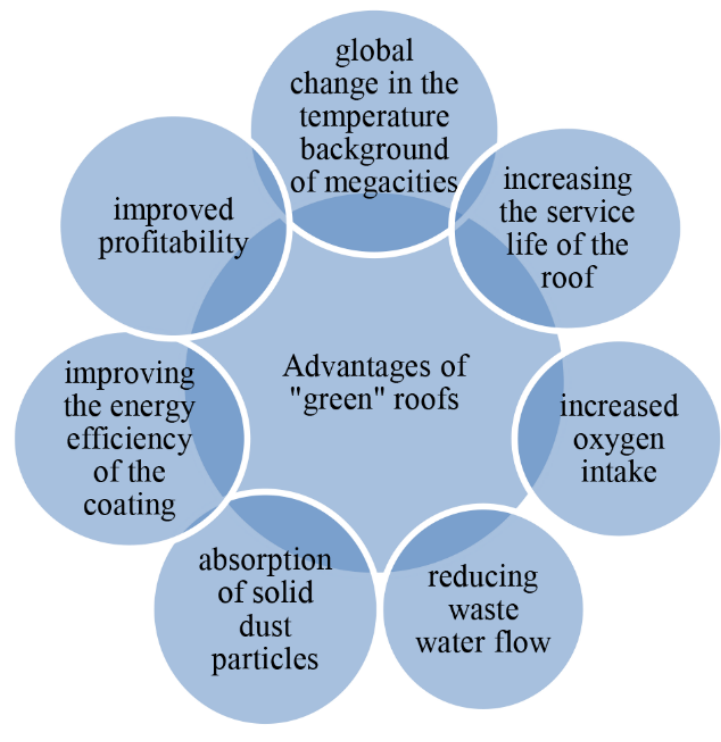

Fig. 1. Advantages of green roofs.

Despite the fact that over the past 1-2 decades, some efforts have been made to thoroughly understand and confirm the environmental effectiveness of green roofs, there has not been a criteria-based methodology for justifying the need for green roofs on the territory of Russia with different climate zones, which hinders the creation of regulatory documents that can legalize the need to create this structure on buildings under construction and reconstructed.

Experimental and analytical researches are needed to create a methodology for scientific justification of the ecological efficiency of the green roof design and the district model, to confirm the need and possibility making of a green roof in the II climatic zone of Russia, taking into account the temperature difference (up to $50^{\circ} \mathrm{C}$ ) in summer and winter seasons.

It can contribute to the wider use of green roofs in Russia when using the scientific potential and relevant technological and innovative developments.

\section{References:}

1. D.V. Chumakov, Science and innovation in the XXI century: current issues, achievements and development trends collection of articles of the winners of the international scientific and practical conference, 113-115 (2016)

2. T. Carter, C. Butler, Cities and the Environment 1.2(9), 17 (2008)

3. A.A. Dolgopolova, Youth and science 1, 3 (2013)

4. Y.Y. Chugunova, E.E. Semenova, Scientific Herald of the Voronezh state University of architecture and construction. Series: High technology. Ecology 1, 230-232 (2015)

5. M.M. Shats, Y.B. Skachkov, Climate and nature 3(32), 3-16 (2019)

6. S.V. Kornienko, E.D. Popova, Constr. of unique buildings and structures 4(55), 67-93 (2017)

7. Jour AU - Kolb, Walter PY - 2004/01/31 SP - T1 - Good Reasons for Roof Planting Green Roofs and Rainwater VL - 643 DO - 10.17660/ActaHortic.2004.643.38 JO - Acta Horticulturae ER

8. A.O. Ioffe, O.I. Gavrilova, Engineering Bulletin of the don 4(51), 215 (2018) 
9. P. Karachaliou, M. Santamouris, H. Pangalou, Energy and Buildings 114, 256-264 (2016)

10. L.D. Kotlikoff, M.V. Kazakova, K.V. Nesterova, Russian business 18(4), 633-640 (2017)

11. S.E. Stetsenko, T.A. Topilin, Questions of tech. and phys. and mathem. Sciences in the light of modern research collection of articles on the materials of the XI international scientific and practical conference, 32-37 (2019)

12. Y.Y. Chudinova, E.E. Semenova, Scientific Bulletin of the Voronezh state University of architecture and construction. Series: High technology. Ecology 1, 230-232 (2015)

13. S.E. Ouldboukhitine, R. Belarbi, R. Djedjig, Building and Environment 56, 78-85 (2012)

14. U. Berardi, Energy and Buildings 121, 217-229 (2016)

15. G. Virk, A. Jansz, A. Mavrogianni, A. Mylona, J. Stocker, M. Davies, Energy and Buildings 88, 214-228 (2015)

16. P.L. Roche, U. Berardi, Energy and Buildings 82, 492-504 (2014)

17. S.V. Kornienko, E.D. Popova, Construction of unique buildings and structures 4(55), 67-93 (2017)

18. B. Raji, M.J. Tenpierik, A. van den Dobbelsteen, Energy and Buildings 124, 210-221 (2016)

19. B. Lin, Y. Liu, Z. Wang, Z. Pei, M. Davies, Energy and Buildings 129, 9-18 (2016)

20. Y. Li, W. Yu, B. Li, R. Yao, Energy and Buildings 125, 231-243 (2016)

21. M.J. Kim, M.W. Oh, J.T. Kim. Energy and Buildings 66, 203-210 (2013)

22. L.N. Dwaikat, K.N. Ali, Energy and Buildings 110, 396-403 (2016)

23. Y. Liu, X. Guo, F. Hu, Energy and Buildings 82, 37-46 (2014)

24. C.M. Silva, M.G. Gomes, M. Silva, Energy and Buildings 116, 318-325 (2016)

25. J. Sproul, M.P. Wan, B.H. Mandel, A.H. Rosenfeld, Energy and Buildings 71, 20-27 (2014)

26. Y. Li, R. Babcock, Agr. for Sust. Dev., Springer Verlag 34(4), 695-705 (2014)

27. F. Municipal Green Roof Strategies. Inventory, Potential Analysis, Practical Examples. The German roof gardener Association (DDV) (2016)

28. E. Korol, N. Shushunova, MATEC Web of Conferences 06014 (2017)

29. A.I. Kopylova, AlfaBuild 2(2), 18-22 (2017)

30. N. Abualfaraj, J. Cataldo, Y. Elborolosy, D. Fagan, S. Woerdeman, T. Carson, F.A. Montalto, Water 10(11) (2018) doi:10.3390/w10111494

31. S.R. Gaffin, R. Khanbilvardi, C. Rosenzweig, Center for Climate Systems Research (Columbia University, New York) https://doi.org/10.3390/s90402647

32. Jun Yang, Qian Yu, Peng Gong, Atmospheric Environment 42, 7266-7273 (2008)

33. Jian-Feng Li, Jie-Min Zhan, Y.S. Li, Onyx W.H. Wai, Environmental pollution (Barking, Essex: 1987) 177, 4-12 (2013)

34. T. Tkachenko, V. Mileikovskyi, A. Ujma, CzOTO 2019 1(1), 419-424 (2019)

35. L.A. Scherer, Comparing experimentally measured runoff coefficients with field observations for detention-based roofs (Norwegian University of Science and Technology, Trondheim, 2018)

36. M.-C. Gromaire, D. Ramier, M. Seidl, E. Berthier, M. Saad et al., NOVATECH 2013 (Lyon, France, 2013) 
37. D. Ramier, E. Berthier, B. de Gouvello, $11^{\text {th }}$ International Conference on Urban Drainage Modelling (Palermo, Italy, 2018)

38. J. Sage, C. Bonhomme, E. Berthier, M.-C. Gromaire, Journal of Environmental Engineering 143(2), 04016077 (2016) DOI: 10.1061/(ASCE)EE.1943 7870.0001163.

39. B. Gisvold Johannessen, V. Hamouz, A. Seifu Gragne, T. Merete Muthanna, Journal of Hydrology (2019) doi: 10.1016/j.jhydrol.2019.01.004.

40. Federal law on energy saving and energy efficiency improvement, and on amendments to certain legislative acts of the Russian Federation of 23.11.2009 N 261-FZ

41. N.V. Pilipenkov, Heat losses and energy efficiency of buildings and structures: textbook. Manual (Saint Petersburg ITMO University, 2016)

42. N.A. Grigorieva, Trudy BSTU. Series 5: Economics and management 2(202), 80-85 (2017)

43. V.V. Balagurov, E.V. Komova, A.E. Bezrodnov, P.G. Gravdina, P.A. Pankov, Don's engineering Bulletin 4(51), 172 (2018)

44. E.V. Sysoeva, M.O. Gelmanova, Construction and reconstruction 2, 105-112 (2018)

45. E. Sysoeva, M. Gelmanova. AISC 982, 186-198 (2020) DOI: 10.1007/978-3-03019756-8_18

46. I.V. Aksenov, E.V. Sysoeva, Innovations and investments 9, 176-179 (2018)

47. K.S. Foshinam, Step into science 3, 89-91 (2018)

48. SP 50.13330.2012. Thermal protection of buildings (Ministry of regional development of Russia, Moscow, 2012) 